\title{
Ingestive behaviour of sheep and goats grazing in a landscape mosaic
}

\author{
M Trabalza-Marinucci ', V Abbadessa 2, M Antonini 2, C Cavallucci ${ }^{1}$, O Olivieri ${ }^{1}$ \\ 1/stituto di Produzioni Animali, Facoltà di Medicina Veterinaria, 06126 Perugia ; $2 E N E A$, CRE Casaccia, \\ INN-BIOAG-PAN, 00060 S Maria di Galeria, Roma, Italia
}

The understanding of the effects of grazing and browsing on the vegetation dynamics has relevance to the management of marginal areas and to landscape and nature conservation. There is a little information available on the ingestive behaviour of small ruminants foraging in a landscape mosaic. Consequently, a great part of natural marginal habitats have been transformed through uncontrolled ecological changes.

The experiment was carried out in a typical hilly area of Central Italy, characterized by the occurrence of two major plant communities (PC) : grassland, dominated by Poa pratensis and Trifolium spp., and forest, where Carpinus betulus and Juniperus oxycedrus were the dominant woody species. The area was used and partly overgrazed during the years prior to the experiment by sheep, goats, cattle, and horses. The animals used in the experiment were 18 Heidschnucken sheep and 16 Alpine and Spanish-type goats, distributed in three homogeneous 5-hectare plots according to the following scheme : only sheep (S) ; only goats (G) ; sheep and goats in equal proportion (GS). Animals were allowed to graze from 800 to 1800 each day at similar grazing pressures (50 $\mathrm{kg} \mathrm{MW/ha),} \mathrm{and} \mathrm{penned} \mathrm{at} \mathrm{night} \mathrm{in} \mathrm{enclosed}$ sheds.

Sampling and observations were performed monthly over a period of 12 months. Recording of ingestive behaviour was begun $30 \mathrm{~min}$ after the animals had entered the areas. Bite rate (BR) was measured over a 2-min period every 10 min of foraging. Bite size dry matter (BS) was determined by hand-plucking. Herbage availability was determined monthly by harvesting individual species of grasses and forbs in 5 randomly located $1-\mathrm{m}^{2}$ in each plot. Sward height was recorded as the mean of 100 random determinations. Shrub and tree biomass was estimated according to Pfister and Malechek (1986, J Range Manage, 39, 24-28).

The average sheep $\mathrm{BR}$ was higher than goats $B R$, but goats showed a significantly higher BS. This led to an increase in live weight which was similar between species (13\% and $16 \%$ for goats and sheep, respectively). Grazing BR was higher and grazing BS lower in plot GS, compared to plots $G$ and $S$, for both species and was related to a reduction in available herbage biomass and sward height; the average DM intake rate/min (IR) did not differ between plots for goats ( $\mathrm{G}: 7.26 \mathrm{~g}$; GS : 7.69) and was only slightly different for sheep (S : $7.97 \mathrm{~g} ;$ GS : $6.11 \mathrm{~g}$ ). There was a significant interaction $(P<0.001)$ between season and class of forage (graze-browse) on BR, BS, and IR in sheep and goats. The lowest grazing $B R$ was recorded in summer, the lowest browsing BR in winter and fall. Grazing BS through the seasons was more consistent in goats than sheep: BS for browsing decreased in spring. Goats were able to maintain a similar IR during the whole year (9.02 $\mathrm{g}$ in spring to $10.99 \mathrm{~g}$ in summer). Sheep IR varied between $6.33 \mathrm{~g}$ in winter and $7.59 \mathrm{~g}$ in spring. $B R, B S$, and IR were not influenced by $P C$ and period of the day.

Sheep and goats were able to adjust their ingestive behaviour to the changes in forage availability. Goats showed a greater ability in using different PC's, while sheep mostly reacted by modifying their grazing time. 